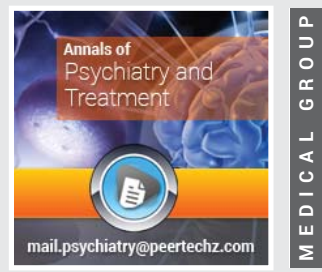

\section{Osundina $\mathrm{AF}^{1 *}$, Fela-Thomas $\mathrm{AL}^{1}$, Akanni $\mathrm{OO}^{\prime}$, Olotu SO', Agbonile $\mathrm{IO}^{1}$ and Akpalaba $\mathrm{RU}^{2}$}

'Federal Neuropsychiatric Hospital, Benin-City, Nigeria ${ }^{2}$ Department of Optometry, University of Benin, Nigeria

Dates: Received: 04 April, 2017; Accepted: 04 July, 2017; Published: 05 July, 2017

*Corresponding author: Osundina AF, Federal Neuropsychiatric Hospital, Benin-City, Nigeria, Tel: +2348037273739; E-mail: osundinaade@yahoo.com

Keywords: Charles Bonnet Syndrome; Visual hallucinations; psychogeriatric; Nigeria

https://www.peertechz.com

\section{Case Report}

Charles Bonnet Syndrome: A Case Series from a Psychogeriatric Clinic in a Tertiary Hospital in Nigeria

\begin{abstract}
Charles Bonnet Syndrome (CBS), also known as visual release hallucinations is the experience of complex visual hallucinations in an individual with partial or severe blindness. It is an uncommon disorder with a worldwide prevalence ranging between $0.5 \%-40 \%$. However, the prevalence in Africa is largely unknown due to unavailability of reliable statistics. Furthermore, there has generally been an under-reporting of visual hallucinations by patients due to fear of being labeled psychologically unstable. As the population of old people increases in our society, there is also the likelihood of an increase in visual impairment among them and consequently an increase in those affected by CBS. We therefore report the two cases of this uncommon disorder that presented in our psychogeriatric clinic in order to raise awareness among clinicians with the aim of encouraging early detection and prompt treatment in a resource constrained setting like Nigeria.
\end{abstract}

\section{Introduction}

Charles Bonnet Syndrome (CBS) is a rare disorder characterized by the presence of vivid, complex and recurrent visual hallucinations not occurring as a result of delirium [1]. The disorder usually occurs in elderly individuals who are visually impaired as a result of age-related macular degeneration [2]. However other causes such as retinitis pigmentosa, severe myopia, glaucoma, cataract, diabetic retinopathy and optic neuritis have been reported [3].

CBS usually occurs following abrupt and unexpected loss of vision and has not been found to occur with lifetime blindness [4]. The experience of hallucinations in the disorder are considered to occur as a result of a 'release phenomenon' secondary to the de-afferentation of the cerebral cortex [5].

With normal vision, the information received from the eyes stops the brain from releasing its own pictures. However in blindness, the information reaching the brain is grossly reduced and the brain now fill in these gaps by releasing fantasy pictures, patterns or old pictures it had stored thereby resulting in hallucination [6].

The content of the hallucination varies and may include images of people, animals, plants and inanimate objects. These images may be familiar or strange to the individual and may appear in different colours. Individuals may experience different hallucinations in each episode and they are usually unable to influence the hallucinations [7], some patients have reported images lasting for varying length of time from seconds to hours. These hallucinations may be triggered by factors such as changes in the degree of illumination, stress and fatigue [8].

There is an under-reporting of CBS in our environment because many cases presenting in the psychiatric clinics are misdiagnosed as either Schizophrenia or Organic mental disorder due to the prominence of visual hallucinations. We report these two cases of CBS in order to improve the level of awareness amongst medical professionals about this relatively uncommon disorder.

\section{Case 1}

A 60 year old married clergyman presented at the psychogeriatric clinic of the hospital with complaints of poor vision and recurrent experiences of seeing frightening figures not seen by others in clear consciousness of about 5 years duration.

The visual experience was described as frightening because the client reported seeing graves of dead bodies, or human skulls hanging on the wall which other people could not see. This usually lasts for a few minutes and it happens a number of times in a day. There was no associated history of head injury or use of psychoactive substances. 
The visual hallucinations occurred following history of poorly controlled, longstanding hypertension, and a diagnosis of glaucoma about 21 years prior to presentation. Patient however defaulted on follow-up from the teaching hospital where he was receiving treatment for the visual impairment.

There were no other psychotic symptoms such as delusions, or hallucinations in other modality apart from visual hallucinations, and there were no abnormalities of thought form, content and possession, or extremes of motor activity or disorganized speech. He had no prominent mood or anxiety symptoms. There was no previous history of a psychiatric illness and there was no history suggestive of a mental disorder in any of his first degree relatives.

There was no impairment in various domains of functioning except in areas directly involved with vision.

In managing the case, patient was educated about the nature of the illness and was advised to continue with his followup with the ophthalmologist. He was given a prescription of tabs trifluoperazine 10mg nocte because he reported being significantly distressed on account of the recurrent frightening experiences which had resulted in severe agitation on several occasions. He was given a clinic appointment of one month.

During his subsequent visit, he reported that the frequency of having the visual hallucinations had reduced. He however gave information that he was yet to be further reviewed by the ophthalmologist due to financial constraints. After about eight months, he defaulted from the psycho-geriatric clinic.

\section{Case 2}

A 73 year old man presented at the psychogeriatric clinic on account of repeatedly seeing images not seen by others. He usually sees these images frequently in clear consciousness and described these images as vivid in nature. He reported always seeing a woman and a man having sex although no other person around him has ever seen these images.

He described this scene as frightening. On several occasions, he sees white people but no other person around him sees them. He agreed to the fact that these images were not real.

He does not have hallucinations in any other modality apart from visual. He denied any previous history of a mental illness. There was no history of a family history of mental illness. He also denied the use of psychoactive substances. There was no gross impairment in his occupational and social functioning and his personality was fairly stable.

He was diagnosed with bilateral cataract and glaucomatous optic atrophy 10 years prior to the onset of the visual hallucinations. He had left eye surgery following diagnosis of matured cataract which was not successful. He still attends follow up at the ophthalmology clinic and stated below are details of his eyes examination which were made available by the ophthalmology team.

Visual acuity: No light perception in both eyes.
Anterior segment examination (both eyes): Normal eye lids, conjuctival injections, clear cornea, deep anterior chambers, afferent papillary defects i.e. unreactive pupils, lens opacities.

Fundoscopy of the right eye was precluded by dense lens opacity.

Left eye revealed a pale disc, with cup to disc ratio of 0.8 , nasalized vessels.

Intraocular pressure was $17 \mathrm{mmHg}$ and $18 \mathrm{mmHg}$ in the right and left eye respectively.

Assessment: 1. Right senile cataract

2. Glaucomatous optic atrophy

\section{Management by the psychiatric team}

Patient was counseled about the nature of the illness at presentation and was given a prescription of antipsychotic medication (I.M Fluphenazine decanoate $25 \mathrm{mg}$ stat) because he found the experience frightening. He was initially stable on the injection for some years until he defaulted from the ophthalmology clinic and the visual hallucinations became worse. In view of worsening of symptoms, he was then given a prescription of tab sodium valproate $400 \mathrm{mg}$ nocte and tab risperidone $1 \mathrm{mg}$ nocte. He is currently stable on these medications.

\section{Discussion}

In elderly patients, visual hallucinations occur as a result of some medical disorders such as dementia, delirium or drug-induced states [9]. However, in CBS, there is usually a triad of visual impairment, clearly formed vivid and recurrent hallucinations and preserved cognitive status [10], as is the case in both elderly men.

In the past, there were controversies regarding visual impairment as an important component of the disorder [4]. However, in recent times, it has been widely accepted that visual loss is required as part of the symptoms for diagnosis [9]. In the second case of this report; it was found that the failing eye sight worsened the visual hallucination. This finding is consistent with previous reports on cases of Charles Bonnet Syndrome.

The prevalence of CBS is understandably higher among the geriatric population. Some of them report improvement or resolution of symptoms after several years though this is not the finding with the second case who has been on follow up for some years. The first case reported has not been sufficiently followed up to comment on long term outcome of the syndrome before he defaulted.

A few of those diagnosed with CBS may not be bothered by the visual hallucinations especially those who have been educated about the cause and nature of the illness. This category of patients may not require pharmacological intervention. However, the visual hallucinations may be distressing in some patients and these ones may likely benefit from medications. 
Pharmacological agents such as antipsychotics, Selective Serotonin Reuptake Inhibitors (SSRIs) and anticonvulsants have been tried but the evidence for treatment remains limited [11].

\section{Conclusion}

We have highlighted cases of two elderly men who presented at the psychogeriatric clinic of our hospital with features of Charles Bonnet Syndrome. This is aimed at improving knowledge and early detection among clinicians with the overall aim of reducing suffering among patients.

\section{References}

1. Oliver S (2016) Charles Bonnet Syndrome. Vojnosanitetski Pregled 73: 881 884. Link: https://goo.gl/VAUa23

2. Pierre-Francois K, Francois-Xavier B (2009) acute reversible Charles Bonnet Syndrome precipitated by sudden severe anaemia. European Journal of Ophthalmology 19: 494-495. Link: https://goo.gl/aNQqpM

3. Lapid MI, Burton MC, Chang MT, Rummans TA, Cha SS (2013) Clinical phenomenology and mortality in Charles Bonnet syndrome. Journal of Geriatric Psychiatry and Neurology 26: 3-9. Link: https://goo.gl/QCE2A2
4. Menon GJ, Rahman I, Menon SJ, Dutton GN (2003) Complex visual hallucinations in the visually impaired: The Charles Bonnet Syndrome. Survey of ophthalmology 48: 58-72. Link: https://goo.gl/jGSDfd

5. Menon G (2005) Complex visual hallucinations in the visually impaired: A structured history-taking approach. Archives of Ophthalmology 123:349-355. Link: https://goo.gl/KrrgVN

6. Teunisse RJ, Cruysberg JR, Hoefnagels WH, Verbeek AL, Zitman FG (1996) Visual hallucinations in psychologically normal people: Charles Bonnet's Syndrome. Lancet 347: 794-797. Link: https://goo.gl/phkrKr

7. Ffytche D (2007) Visual hallucinatory syndromes: past, present and future Dialogues in Clinical Neuroscience 9: 173-189. Link: https://goo.gl/UL3uKY

8. Brucki S, Takada L, Nitrini R (2009) Charles Bonnet Syndrome: case series. Dementia Neuro-Psychologia 3: 61-67. Link: https://goo.gl/KjL3uc

9. Jackson M, Ferencz J (2009) Charles Bonnet Syndrome: visual loss and hallucinations. Canadian Medical Association Journal 181: 175-176. Link: https://goo.gl/uDibyi

10. Abhijit Chaudhuri (2000) Charles Bonnet Syndrome: an example of cortical dissociation syndrome affecting vision? Journal of Neurology, Neurosurgery and Psychiatry 69:704-705. Link: https://goo.gl/n55BTS

11. Hartney K, Catalano G, Catalano M (2011) Charles Bonnet Syndrome: are medications necessary. Journal of Psychiatric Practice 17: 137-141. Link: https://goo.gl/epNvNG 